\title{
INSUBORDINAÇÃO CRIATIVA E A CYBERFORMAÇÃO COM PROFESSORES DE MATEMÁTICA: DESVELANDO EXPERIÊNCIAS ESTÉTICAS POR MEIO DE TECNOLOGIAS DE REALIDADE AUMENTADA $^{1}$
}

\section{CREATIVE INSUBORDINATION AND CYBEREDUCATION WITH MATHEMATICS TEACHERS: UNCOVERING AESTHETIC EXPERIENCES THROUGH AUGMENTED REALITY TECHNOLOGIES}

\author{
Maurício Rosa \\ Universidade Federal do Rio Grande do Sul (UFRGS) - Faculdade De Educação - Departamento \\ de Ensino e Currículo - mauriciomatematica@gmail.com
}

\section{Resumo}

Esse artigo objetiva apresentar uma pesquisa em andamento que estabelece interfaces com a concepção de Insubordinação Criativa. A investigação sobre as experiências estéticas promovidas com Tecnologias Digitais (TD) de Realidade Aumentada ${ }^{2}$ (RA), enquanto transformadoras/potencializadoras da Cyberformação com professores de matemática $^{3}$, almeja entender a construção de atividades-matemáticas-com-TD de RA e a utilização dessas em sala de aula, de modo a promover a criatividade tecnológica e a subversão da grade curricular. A RA é considerada a inserção de objetos virtuais no ambiente físico, com o uso de algum dispositivo tecnológico. A Cyberformação, por sua vez, é uma concepção que abrange a formação vista sob as dimensões específica (matemática), pedagógica e tecnológica que assume o trabalho com TD, sob a perspectiva do ser-com, pensar-com e saber-fazer-com-TD. As experiências estéticas (baseadas no "belo", no fascinante, em termos de imagem, movimento...), expressas evocativamente, talvez estabeleçam uma teia de relações entre "presença" e "vivência" na "pele" e no "contexto matemático" a ser criado, imaginado e experienciado com as TD de RA por

\footnotetext{
${ }^{1}$ Esse artigo é resultado parcial de uma pesquisa em andamento que foi apresentada por meio de pôster no I ICOCIME (International Conference on Creative Insubordination in Mathematics Education), com apoio do CNPq - Universal Processo 486260/2013-5.

${ }^{2}$ Realidade Aumentada é considerada a "[...] inserção de objetos virtuais no ambiente físico, mostrada ao usuário, em tempo real, com o apoio de algum dispositivo tecnológico, usando a interface do ambiente real, adaptada para visualizar e manipular os objetos reais e virtuais" (KIRNER; KIRNER, 2008 apud SOUZA; MOREIRA; KIRNER, 2012).

3 "Compreendendo o entrelaçamento entre a subjetividade dos sujeitos de sujeitos viventes, a intersubjetividade e a objetividade do expresso e acordado intersubjetivamente, afirmamos que há a "Matemática" com letra maiúscula, aquela que pelo Formulário Ortográfico de 1943 - Oficial no Brasil, indicava em seu sexto artigo que se usava letra maiúscula "Nos nomes que designam artes, ciências ou disciplinas, bem como nos que sintetizam, em sentido elevado, as manifestações do engenho e do saber" (PORTAL DA LíNGUA PORTUGUESA, 2015 - grifo nosso). Conforme Vanini (2015) por muito tempo ela foi defendida como soberana, denominada a matemática universitária, matemática ocidental, a qual é estruturalmente demonstrável e axiomática. De outra perspectiva compreendemos a defesa de outra matemática que não é a disciplinar, ainda que não desconsidere a sua importância. Trata-se de um fazer matemático que busca pelo sentido do que está sendo realizado. Esse modo de entendê-la tem levado a escrevê-la com letra minúscula, com a intenção de evidenciar que se está em um campo em que a relação de poder estabelecida por aqueles que dominam a disciplina Matemática não está presente. É um modo de compreender a matemática e de escrevê-la com letra minúscula e que está em sintonia com o Acordo Ortográfico da Língua Portuguesa de 1990, oficializado em 2009 que traz na Base XIX - das minúsculas e maiúsculas - que as letras minúsculas são usadas nos nomes que designam domínios do saber, cursos e disciplinas (opcionalmente, também com maiúscula): português (ou Português), matemática (ou Matemática); línguas e literaturas modernas (ou Línguas e Literaturas Modernas)" (PORTAL DA LíNGUA PORTUGUESA, 2015 - grifo nosso)" (ROSA; BICUDO, 2018,p. 7).
} 
docentes (participantes da produção de dados) e por seus alunos. Isso leva-nos a pensar em uma ruptura em termos de "seguir a receita" quando se trata de uso de TD em aula.

Palavras-chave: Educação Matemática; Experiência Estética; Cyberformação com professores de matemática; Insubordinação Criativa.

\begin{abstract}
This article aims to present an ongoing research that establishes interfaces with the Creative Insubordination concept. The research on aesthetic experiences promoted with Digital Technologies (DT) of Augmented Reality (AR), as transformers/potentiators of Cybereducation with mathematics teachers, aims to understand the construction of mathematical activities-with-DT of AR and the use of those in classroom, in order to promote technological creativity and the subversion of the curriculum. The AR is considered the insertion of virtual objects in the physical environment, with the use of some technological device. Cybereducation, in turn, is a conception that encompasses the education seen under the specific (mathematical), pedagogical and technological dimensions that assume the use of DT, from the perspective of being-with, think-with and know-how-to-do-with-DT. The aesthetic experiences (based on "beauty", fascinating in terms of image, movement ...), that were evocatively expressed, perhaps will establish a web of relations between "presence" and "experience" in the "skin" and in "mathematical context" which was created, imagined and experienced with AR by teachers (participants in data production) and by their students. This leads us to think of a break in terms of "following the recipe" when it comes to use of DT in class.
\end{abstract}

Keywords: Mathematics Education; Aesthetic Experience; Cybereducation with mathematics teachers; Creative Insubordination.

\title{
Insubordinando criativamente a prática pedagógica com TD
}

[...] Desde criança tive a tendência para criar em meu torno um mundo fictício, de me cercar de amigos e conhecidos que nunca existiram. (Não sei, bem entendido, se realmente não existiram, ou se sou eu que não existo.

Nestas cousas, como em todas, não devemos ser dogmáticos.) Desde que me conheço como sendo aquilo a que chamo eu, me lembro de precisar mentalmente, em figura, movimentos, carácter e história, várias figuras irreais que eram para mim tão visíveis e minhas como as cousas daquilo a que chamamos, porventura abusivamente, a vida real. Esta tendência, que me vem desde que me lembro de ser um eu, tem-me acompanhado sempre, mudando um pouco o tipo de música com que me encanta, mas não alterando nunca a sua maneira de encantar [...]

(Fernando Pessoa - Trecho da Carta a Adolfo Casais Monteiro, 1935) 
O ato necessário de se cercar mentalmente de amigos constituídos em figura, movimentos, caráter e história, do qual Pessoa (1935) fala, para mim, também acontece há longa data e permanece como um jogo, o qual pode ser visto como um jogo de palavras, de interpretações, de posicionamentos e de identidades, em um contexto específico. Foi esse jogar, próprio da minha vida, que estabeleceu a proposta de desenvolvimento de uma pesquisa científica que investigasse a construção de "eus" em função do ensino e da aprendizagem de matemática, a partir de um cenário materializado tecnologicamente (ROSA, 2008). Esses "eus", os quais são outros, mas que continuam sendo "eu", ou ainda "eus" precisos mentalmente em figura, movimentos, caráter e história, se mostram de forma particular em ambientes cibernéticos e constituem pontes cognitivas específicas. Essas pontes são frutos de interações com o mundo, com os outros e consigo mesmo. Desse modo, desvendar as relações entre os processos de construção, como a ação de projetar os "eus" e desenvolver algo, serviu como objeto de investigação, uma vez que o cerne do estudo mencionado esteve nas relações estabelecidas entre a construção do "ser" e o ensino e a aprendizagem de matemática. Entretanto, qualquer pesquisa deve centrada em uma temática, persegue um foco, mas caminha em torno sempre. $\mathrm{Na}$ verdade, acontece um movimento circular que persegue o entorno, esclarecendo-o, clarificando-o. Esse movimento abre outras prerrogativas, outras ideias surgem e, assim, se manifestam como focos de outras possíveis investigações. Essas avançam em termos materiais, metodológicos, teóricos, e, muitas vezes, ainda mantém em seu âmago um caminhar característico, diferenciado, arredio, crítico, insubordinado, subversivo.

No meu caso, acredito que a pesquisa envolvendo tecnologias e Educação Matemática, cada vez mais, se torna necessária e abre possibilidades à subversividade responsável. É devido ao desenvolvimento das Tecnologias Digitais que pesquisas ligadas à Educação Matemática e que investigam o uso dessas, tornam-se frequentes. Isso acontece, pois, essas tecnologias têm modificado a sociedade em quase todas as áreas e, sendo assim, o campo educacional não é exceção, muito pelo contrário, trata-se de uma área em que essas tecnologias apresentam um potencial considerável (ROSA, 2008, 2015; BULLA; ROSA, 2017), diferentes recursos tecnológicos vêm sendo pesquisados e, muitas vezes, desenvolvidos: Calculadoras Gráficas (DUNHAM; DICK, 1994; SCUCUGLIA, 2006), Softwares de Geometria Dinâmica (JAHN, 2000), Jogos Eletrônicos (ROSA, 2004), Smartphones (MUSSATO; ROSA, 2012, MOURA, 2014, CALDEIRA, 2016), recursos de RA (BULLA, 2016; MACHADO, 2016, RESENDE, 2016) são alguns recursos tecnológicos que apresentam suas potencialidades e limitações nas pesquisas de cunho educacional e que por vezes acabam desestruturando práticas convencionais, cotidianas e rotineiras. No entanto, pesquisas em Educação Matemática, na maioria das vezes, tratam do uso de tecnologias com estudantes como forma de motivar o interesse e/ou o estudo de matemática por parte desses (NUNES, 2011) e, em vários casos, trazem o não uso de tecnologias por parte do professor como resultado de lacunas na formação (VANINI et al., 2013) e/ou pelo fato do professor buscar manter-se no que Penteado (2001) denomina de "zona de conforto", uma vez que, o uso de tecnologias pode gerar uma "zona de risco". 
Nesse sentido, de acordo com D'Ambrosio e Lopes (2015, p. 1) há "[...] a necessidade de a comunidade reinventar as práticas da Educação Matemática [...] [isto é] atrever-se a criar e ousar na ação docente decorre do desejo de promover uma aprendizagem na qual os estudantes atribuam significados ao conhecimento matemático". Nessa perspectiva, a meu ver, surge um campo ainda não investigado, o qual é ousado em termos de ação docente, pois trabalha com a criatividade do professor e também do seu aluno, em nível fundamental e médio, ao propor o desenvolvimento de atividadesmatemáticas-com-Realidade Aumentada, de um tópico matemático possível, por exemplo, funções de uma variável real, a partir do estudo de funções de duas variáveis reais (tópico matemático atribuído ao Ensino Superior nas grades curriculares).

A Realidade Aumentada é compreendida, a partir de uma das definições mencionadas por Kirner e Siscoutto (2007), como um ambiente real enriquecido com objetos virtuais, criados a partir do uso de algum dispositivo tecnológico, operando em tempo real. Dessa forma, os objetos virtuais de RA podem ser criados a partir de um smartphone ou de um tablet instalados com um aplicativo específico. Assim, cabe pensar nesses dispositivos inseridos no cenário educacional em termos de Educação Matemática, mas, acima de tudo, entender de que modo esses recursos possibilitam uma sensação de envolvimento, denominado por muitos como "motivação" e que, do mesmo modo, carregam consigo outro sentimento que pode ser empiricamente evidenciado como "barramento/medo" de explorá-los.

Pei-Luen, Qin e Li-Mei (2008) discutem motivação dos estudantes e pressão geradas pelo uso de dispositivos de comunicação móvel na educação. No caso do que entendem como motivação, ainda não se identificou o porquê do suposto fascínio do uso de Tecnologias Digitais por parte dos estudantes (na maioria, participantes da geração net) e a contribuição que esse sentimento traz à Educação. No caso da pressão, essa é muitas vezes evidenciada, quando há expressão pública em vez de diálogo privado nas comunicações estabelecidas.

$\mathrm{Na}$ Educação Matemática, é necessária a compreensão tanto da conexão "atrativa" para a produção do conhecimento, por parte dos estudantes que utilizam TD, quanto à possibilidade do uso desses dispositivos tornarem-se um aspecto necessário e entendido, por parte dos professores. Essa compreensão do fascinante e do que pode gerar pressão, talvez seja ainda mais frequente, potencializada, se considerarmos o uso de Tecnologias Digitais de Realidade Aumentada.

O smartphone é um exemplo de recurso que poderá fornecer o feedback da ação tátil, do movimento, do modo de participação do envolvido no processo de estudo, de produção de conhecimento matemático com RA, ampliando a sensação evidenciada no uso das Tecnologias Digitais (computadores, calculadoras gráficas, ...) atualmente. Entendo, então, que inserir essas interfaces no contexto educacional matemático fornece um leque de situações a serem analisadas para que possamos ampliar e/ou potencializar o ensino e a aprendizagem de matemática, mesmo gerando uma situação que promova um "barramento/receio" do professor quanto ao uso do "novo", da tecnologia, daquilo que não domina. Frente ao exposto por D'Ambrosio e Lopes (2015), busco com os procedimentos da própria pesquisa, questionar as formas como a matemática pode ser 
produzida na escola, quando se utiliza TD; enfatizar a humanidade e a incerteza da disciplina de Matemática e do uso de Tecnologias Digitais em sala de aula; posicionar tanto os alunos como autores da matemática, quanto os professores como autores de práticas educativas com TD de RA; e desafiar os discursos discriminatórios sobre o uso de smartphones em sala de aula (prática a ser orientada como insubordinação criativa).

Para que isso ocorra, acredito que a formação com o professor de matemática frente ao uso dessas TD é um aspecto que deve ser investigado. Inicialmente, em termos de sua intencionalidade (BICUDO; ROSA, 2010) ao lidar com essas interfaces, em seguida, frente a seu posicionamento (do professor) ao propor atividades educacionais com esses recursos em ambientes educacionais de nível fundamental e médio. Conceitos matemáticos como, por exemplo, o de funções de uma variável real, podem ser discutidos por meio de atividades que trabalhem com funções de duas variáveis reais, a partir de experiências "vivenciadas" com as Realidades Mundana ${ }^{4}$, Virtual e, consequentemente, Aumentada. Isso, em termos curriculares, também se torna uma insubordinação, pois, trata dos processos de pensamento como eixos balizadores de um currículo e não os conteúdos (ROSA; BAIRRAL, 2015). Há, então, a busca por uma subversão dos valores estéticos da matemática, os processos de pensamento sobre funções de duas variáveis reais não mais precisam ser tratados como intrínsecos ao Ensino Superior.

É importante que avancemos em pesquisas que estudem essa relação evidenciada no uso de Tecnologias Digitais, com esse tipo de recurso tecnológico, para que haja o reconhecimento do porquê do uso e suas potencialidades. Assim, a partir de uma análise crítica, revelar à sociedade acadêmica e à sociedade como um todo, os resultados constatados frente a esse uso.

Corroborando Martins (2003, p. 92) que revela que "[...] as novas tecnologias da comunicação e da informação apontam novas dimensões, que permitem estruturar paisagens educativas mais ricas, variadas e complexas, possibilitando, por exemplo, 'incluir o mundo na aula' e a 'aula no mundo', pretendo, então, investigar as experiências estéticas produzidas com o uso de Tecnologias de RA e evidenciar as possibilidades educacionais frente às relações que são tecidas com o universo da Educação Matemática.

Com isso, ao trabalhar com Tecnologias Digitais de RA, essa pesquisa objetiva investigar as experiências estéticas promovidas com Tecnologias Digitais enquanto transformadoras/potencializadoras da Cyberformação com professores de matemática, de forma a buscar responder a seguinte pergunta diretriz desse estudo:

"De que modo experiências estéticas possíveis de serem promovidas com o uso de Tecnologias Digitais, em práticas educativas matemáticas, podem transformar/potencializar a Cyberformação com professores de matemática?"

Além da pergunta, destaco também alguns objetivos específicos:

\footnotetext{
4 Trata do mundo-vida, mundo vivido, o qual "[...] como uma totalidade harmonicamente consistente é dado de modo imediato na percepção, ato que confere a cada um de nós, em um primeiro momento, na praticidade do empiricamente vivido, certeza ôntica da sua realidade" (BICUDO; ROSA, 2010, p. 70).
} 
a) Analisar o processo estabelecido de construção de atividades-matemáticas-com-TD de RA ocorrido na Cyberformação com professores de matemática, identificando os aspectos que se sobressaem em termos de insubordinação criativa;

b) Analisar o uso das atividades-matemáticas-com-TD de RA construídas em práticas educacionais dos professores participantes do estudo; $\mathrm{e}$

c) Constituir um aporte teórico que esclareça o porquê do uso de Tecnologias Digitais de RA na Educação Matemática, avançando na concepção e entendimento do processo cognitivo que essas tecnologias possam promover.

Assim, cabe estabelecer nossa configuração teórica enquanto forma de rompimento intelectual de arranjos já pré-definidos ou mesmo categorizados a priori.

\section{InsubordinaçõesTeóricas}

O processo de interação educacional, em uma paisagem móvel de significações, pode transformar continuamente o universo no qual adquirem sentido (ROSA, 2008). Isso faz com que a Realidade Aumentada possa a vir a ser locus de uma diversidade de situações a partir de um espaço móvel de interações, entre conhecimentos e conhecedores, de coletivos inteligentes desterritorializados (LÉVY, 2000a). Nessa perspectiva, a Educação Matemática converge para a virtualidade do próprio contexto, ampliando possibilidades de descrição/expressão, reflexão/discussão, execução e depuração compartilhada de ideias (ROSA, 2008) e, com a disponibilidade de Tecnologias Digitais de RA, essa virtualidade salta aos olhos frente à visualização de gráficos em 3D, por exemplo. Esse fato para mim é significativo, pois investigar esse espaço móvel de interações permite transpor o que D'Ambrosio (2014, p. 160) metaforicamente critica em termos do conhecimento tradicional explícito em ações educativas e pesquisas em Educação Matemática, quando revela que

[...] os pássaros vivendo em uma gaiola alimentam-se do que encontram na gaiola, voam só no espaço da gaiola, comunicam-se numa linguagem conhecida por eles, procriam e repetem-se e só veem e sentem o que as grades permitem. Não podem saber de que cor a gaiola é pintada por fora.

Essa cor a ser vista, a meu ver, pode ser vislumbrada no decorrer da experiência estética (ROSA, 2011), quando a intencionalidade de quem está em formação e em aprendizagem se manifesta ao estar com a TD.

Nessa perspectiva, Bicudo (2010, p. 47) entende experiência:

[...] como essa complexidade que fala: do empiricamente sentido na dimensão da fenomenalidade corporal e que se doa como ponto de partida do conhecimento pré-predicativo e predicativo; da experiência como gerando o sentido mediante o nexo estabelecido por aquilo que se doa à percepção mostrar-se harmonicamente imerso no panorama em que é destacado ao ser percebido; da vivência que expressa a vida e permite, pela sua objetivação, que ela seja interpretada, sempre no limite do indecifrável e do indizível e do expressável e interpretável. Expressão que se deixa descrever, porém sempre com as palavras, as quais trazem 
consigo a historicidade do mundanamente vivido, mas, também, trazem a incompletude na impossibilidade de abarcar-se no dito o que se quer dizer; da experiência vivida que se doa à percepção daquele que a vive, permitindo que, em um ato reflexivo, dê-se conta das marcas do havido na totalidade de sua historicidade que, necessariamente, traz a dos outros e da vida, possibilitando a interpretação de si e do mundo histórico-cultural.

Manifesto o interesse por essa concepção principalmente no que se refere ao nexo estabelecido por aquilo que se doa à percepção mostrar-se harmonicamente imerso no panorama em que é destacado ao ser percebido, pois, para mim, trata da compreensão do que é vivido, trata do processo cognitivo realizado ao se pensar com aquilo que é vivenciado no contexto estabelecido. Assim, essa experiência aqui discutida revela a adjetivação daquilo que em Cyberformação trata da parte digital, do foco cyber do vocábulo e que, nesse caso, se caracteriza pelo aspecto estético que as Tecnologias Digitais, em especial, àquelas de RA, vêm abarcar à sociedade e suas demandas, entre elas, a Educação e a Educação Matemática.

Logo, adotamos a Cyberformação com professores de matemática como uma concepção que abrange "[...] a formação vista sob a dimensão específica (matemática), pedagógica e tecnológica que assume o uso de TD, particularmente, o ciberespaço em ambiente de EaD, sob a perspectiva do ser-com, pensar-com e saber-fazer-com-TD" (ROSA, 2015, p.77). Em específico, o ser-com-TD "[...] além de estar no mundo, cria um novo mundo, ou micromundo [...] (ROSA, 2008, p. 118)", em que, o sujeito necessariamente está "plugado" ao meio tecnológico; o pensar-com-TD pode permitir a construção de conhecimento matemático "[...] nas relações com o mundo e com os outros" (ROSA, 2008, p. 106), que abrange a (trans)formação das ideias matemáticas possíveis com este meio tecnológico (computador, software, vídeo); e o saber-fazer-com-TD "[...] é manifestado pelas ações intencionais efetuadas com o mundo, comigo mesmo e com os outros. Nesse sentido, ações desempenhadas na atividade, na construção de um produto, na prática [...] (ROSA, 2008, p. 136)".

Frente à concepção de Cyberformação ao se pensar-com-o-mundo cibernético, vivenciando-o, experienciando-o, navegando nele por fluxos intermitentes de informação, pode haver a experiência vivida por meio da percepção do ser-com e que, em um ato reflexivo, pensa-se-com esse espaço de fluxos no tempo/espaço que se habita, plugandose, trazendo à tona ações dos outros e da vida, sabendo-fazer-com seus mundos histórico-culturais, quer dizer, habitando-os intencionalmente de uma forma diferenciada daquela vivida na realidade mundana. Nessa perspectiva, "Esta forma de pensar impulsiona a investigação, por ser um processo que envolve intuição, emoção e paixão, sem se limitar à busca de soluções lógicas e racionais para os problemas" (D'AMBROSIO; LOPES, 2015, p. 7).

Não obstante, conforme Turkle (1989, p. 15): "Eu vejo o computador [e todas as TD] a uma luz diferente, não em termos da sua natureza como 'engenho analítico', mas em termos de sua 'segunda natureza' como objecto evocativo, um objecto que fascina, perturba a tranqüilidade e estimula o pensamento". Um objeto que lida com movimentos, imagens, cores, sensações e que pode ser um representante de materiais formatados para 
a experiência estética.

Com esse termo [estética] designa-se a ciência (filosófica) da arte e do belo. [...] [Além disso,] hoje, esse substantivo designa qualquer análise, investigação ou especulação que tenha por objeto a arte e o belo, independentemente de doutrinas ou escolas. [...] Dissemos 'arte e belo' porque as investigações em torno desses dois objetos coincidem ou, pelo menos, estão estreitamente mescladas na filosofia moderna e contemporânea (ABBAGNANO, 2003, p. 367).

A experiência estética me remete, então, à vivência que permite trabalhar/experienciar o belo, ou seja, em nosso contexto, vivenciar as informações e possivelmente produzir conhecimento sendo-com, pensando-com, sabendo-fazer-com-TD, mas que não deixa de focar, intencionalmente, a ideia evocativa do uso desses aparatos tecnológicos, por exemplo. Não deixa de se situar a partir do movimento, da cor, da imagem e todas as relações e/ou links que se façam com esses aspectos para que se produza conhecimento intencionalmente e, em específico, conhecimento matemático.

Nesse sentido, essa intencionalidade, entendida pela fenomenologia como consciência, é movimento que nos liga ao mundo mediante atos de percepção e entropatia e que traz isso que é percebido, enquanto percebido, à consciência que os elabora, expressando o percebido e elaborado pela linguagem, ou seja, comunicando-os e disponibilizando-os ao mundo em modos possíveis de expressão (BICUDO; ROSA, 2010). Esses modos permitem a experiência estética, a qual pode ser considerada como a plenitude do estado contemplativo de cada sujeito, no sentido dado por Bakhtin (2011, p. 21), pois pela "[...] singularidade e pela insubstitutibilidade do meu lugar, em que sou o único a estar situado em dado conjunto de circunstâncias [...]" é que posso lançar-me à descoberta, de forma a participar de uma experiência estética, por meio da contemplaação (BAKHTIN, 2011).

A contemplação é, para Bakhtin (2011), a forma como nos tornamos conscientes das características da realidade. O termo contempla-ação é utilizado nessa grafia, pois, na perspectiva desse autor, ela não é passiva e somente depende do contexto desse sujeito que contempla. Esta ação provoca uma noção de completude ligada ao conjunto de ações que, na posição privilegiada pelo excedente de visão, se toma. Essas "[...] ações podem ser infinitamente variadas em função da infinita diversidade de situações da vida em que eu e o outro nos encontramos num dado momento" (BAKHTIN, 2011, p. 23) podendo gerar tantos horizontes quantos indivíduos disponíveis existirem.

Cada horizonte se completa com o excedente de visão do sujeito em primeiro plano. Para mim, tal fato abre inúmeras possibilidades educacionais. São diversas as ações formativas que podem ser criadas com a Realidade Virtual conectada à Realidade Mundana, ou seja, pela Realidade Aumentada, e que cada vez mais possibilitam experiências estéticas que, a meu ver, podem transformar a produção do conhecimento matemático, sendo subversivas de modo responsável nos espaços educativos vigentes. Essas ações viabilizam um "acontecer" em potência e não em ato, mas que cognitivamente podem favorecer os processos de ensino e de aprendizagem, além de proporcionar um vivenciar qualificado e diferenciado na Realidade (mundana, virtual e 
aumentada). Assim, simulação e experimentação matemática podem ser estudadas com softwares que produzem imagens e movimentos, a partir de recursos de RA que possibilitam a imersão do usuário, no ambiente gerado, a partir dessa tecnologia, de maneira natural.

Por meio da RA o usuário possui uma liberdade para interagir tanto com a realidade mundana quanto com a realidade cibernética. A RA nos proporciona uma experiência qualitativamente diferente de uma decorrida na tela de um computador, em virtude dos objetos estarem "presos" ou "amarrados" apenas à realidade cibernética. Isto é, há possibilidades qualitativamente diferentes em relação à visualização, sensação e compreensão.

Com base nisso, ou seja, nesse suporte material da informação, o qual toma agora não só a rede física como aparato tecnológico, busco entender como formar professores de matemática que possam orientar a produção de conhecimento matemático ancorado no espaço/tempo gerado por um corpo biológico que intencionalmente se propaga no universo tecnológico. Nesse caso, as Tecnologias Digitais que se apresentam são "[...] mais do que simples suportes. Elas interferem em nosso modo de pensar, sentir, agir, de nos relacionarmos socialmente e [...] [construirmos o] conhecimento. Criam uma nova cultura e um novo modelo de sociedade" (KENSKI, 2003, p. 23). Essas tecnologias fazem com que as ações em potência e que agora são desencadeadas também por atitudes naturais, sejam atualizadas, mas que geram uma percepção (MERLEAU-PONTY, 2006) de si e do outro que admite um universo diferente daquele entendido pela física clássica (BICUDO; ROSA, 2010). A nova materialidade do espaço conectado, então, permite uma revisitação, uma releitura do mesmo, uma vez que as manifestações realizadas com o espaço de fluxos podem ser conduzidas, gravadas, reproduzidas, lidas, relidas, transformadas..., atualmente, também, por meio da visualização de objetos virtuais misturados aos objetos mundanos.

Desse modo, a materialidade desse espaço em bits, atualiza as práticas sociais em textos, vídeos, imagens, sons... Permitindo que a informação aconteça por meio de uma pluralidade de meios, assim como, pela combinação desses. Além disso, Tecnologias Digitais possibilitam o ato de estar "plugado" (BICUDO; ROSA, 2010) a um mundo criado, programado, mantendo-se naturalmente no espaço mundano, vivenciando situações simuladas de forma a perceber o entorno, visualmente, auditivamente e sinestesicamente, ou seja, experienciando esteticamente o seu mundo-vida ${ }^{5}$. Isso pode ampliar ainda mais as possibilidades de informação e comunicação, de formação e produção de conhecimento, pois, o uso de dispositivos sensoriais pode estabelecer um universo cognitivo surpreendente, uma vez que estar conectado ao mundo cibernético, para se estudar matemática, pode suscitar inúmeras ações de aprendizagem, por exemplo.

Por parte do professor de matemática, faz sentido que esse possa experienciar o próprio processo de uso de tecnologias. Ou seja, embasado em Rosa (2015, p. 61):

\footnotetext{
5 "[...] Mundo não é recipiente, uma coisa, mas um espaço que se estende à medida que as ações são efetuadas e cujo horizonte de compreensões se expande à medida que se vá fazendo o sentido para cada um de nós e a para a comunidade em que estamos inseridos" (BICUDO, 2010, p. 23).
} 
Não se fala de um estar mecânico; não se pensa em uma formação de uso técnico das tecnologias, como se essas fossem recursos auxiliares ao ensino e à aprendizagem; mas, de uma formação que lida e considera as TD como meios que participam ou devem participar, efetivamente, da produção do conhecimento matemático (no caso).

Para essa concepção, estar conectado à rede significa, então, me plugar quando eu desejar e como desejar de forma simbiótica. Reconhecendo "[...] esse processo autônomo como uma necessidade educativa, e não somente como parte da competência profissional" (D'AMBROSIO; LOPES, 2015, p. 10) e mantendo interações no meu tempo/espaço a esse locus de interações que se constitui com Tecnologias Digitais e se apresenta como um contexto específico.

Essa ideia insere-se no que Deleuze e Guattari (2005) caracterizam como conceito, pois percebo cada locus específico que se constrói com TD, cada um dos seus múltiplos fluxos e sua caracterização contextual, como um plano de imanência.

Deleuze e Guattari (2005, p. 267) afirmam,

Um conceito [então] é um conjunto de variações inseparáveis, que se produz ou se constrói sobre um plano de imanência, na medida em que este recorta a variabilidade caótica e Ihe dá consistência (realidade). Um conceito é, pois, um estado caóide ${ }^{6}$ por excelência; remete a um caos tornado consistente, tornado Pensamento, caosmos mental.

O conceito está intimamente ligado ao seu contexto, ao seu locus, ao mundo que se refere e no qual se constitui, ou seja, ao seu plano de imanência. Desse modo, não existe sem esse plano. Não existe sem se entrelaçar com distintas dimensões do ser, do pensar e do saber-fazer. Com o uso de Tecnologias Digitais, então, diferentes dimensões podem surgir ao se estar conectado ao ambiente cibernético, ao se vivenciar a cibercultura (LÉVY, 2000b) na atual conjectura, pois "[...] educar na cibercultura implica considerar outros modos de pensar, de aprender e de se relacionar" (BAIRRAL, 2004, p. 39) em mundos que se transformam e se expandem com naturalidade.

Assim, quando sou-com-a-tecnologia, penso-com-essa, aprendo-a-fazer-com-amesma, há transformações que ocorrem por meio dessas ações, uma vez que, "A tecnologia muda a nossa natureza enquanto pessoas, muda as nossas relações e a percepção que temos de nós mesmos" (TURKLE, 1997, p. 346). Nesse sentido, são esses dispositivos/interfaces que possibilitam a experiência de estar em outro mundo, com objetos que podem, muitas vezes, não fazer parte do nosso cotidiano de forma natural, ao se interagir com essa realidade estando mundanamente situado.

O importante aqui, então, é chamar a atenção para o papel dessas interfaces no pensar-com, além de identificar as possibilidades educacionais que ainda possam ser geradas por elas. Entendo que perceber o gráfico já é algo que mobiliza a produção do conhecimento, pois, no momento em que se compreende, com as Tecnologias Digitais, a sua forma, estrutura, composição, ao se realizar uma movimentação com o dedo (a partir

6 "Chamam-se de caóides as realidades produzidas em planos que recortam o caos" (DELEUZE, GUATTARI, $2005, \mathrm{p}$. 267). 
do toque, por exemplo) ou mesmo com um tipo de mobilização similar a efetuada com uma lente de aumento (lupa) no espaço mundano, porém, com o uso do smartphone, pode-se alterar significativamente a compreensão do objeto matemático com que se está trabalhando.

Essa interação poderá servir como um espelho que reflete o pensar, explicitando-o; que pode dar o feedback ou tornar-se espaço desse feedback; ou mesmo, pode vincularse ao processo de reflexão de forma quase orgânica, simbiótica, uma fusão massiva com o humano que também é indispensável neste processo.

Com isso, situações de formação, de ensino e de aprendizagem podem "ganhar vida" nesses espaços conectados. Elas podem acontecer de diversas maneiras que não se limitam a uma sala de aula, com lousa e giz. A aprendizagem, então, pode acontecer em diferentes cenas, em diversas situações, a partir do sentir-se imerso, sentir-se situado em uma atmosfera que circunda uma identidade que se constrói nesse situar-se.

Assim, corroboro o que diz Murray (1997, p. 99 - tradução nossa ${ }^{7}$ ):

Apreciamos o mundo familiar em movimento, o sentimento de distração que vem de estarmos neste lugar novo, e o prazer que vem de aprender a mover-se dentro dele. A imersão pode envolver um mero inundar da mente com sensação, o transbordamento do estímulo sensório experienciado na sala do televisor em Bradbury's Fahrenheit 451 [romance de ficção científica em que todos os livros do mundo são queimados]. Muitas pessoas ouvem música dessa maneira, como um afogamento prazeroso das partes verbais do cérebro. Mas no meio participativo, a imersão implica em aprender [...] a fazer as coisas que o novo ambiente torna possível.

A matemática estudada com Tecnologias Digitais, a partir deste ponto de vista, então, torna-se favorecida pela construção e exploração de mundos artificiais destinados a diferentes leituras dos conceitos vinculados a essa região de inquérito. $O$ estar plugado pode possibilitar o estar exposto ao micromundo constituído, às mídias presentes nesse, ao ser que se mostra, assim como, à matemática subjacente aos mesmos.

Dessa forma, acredito que "Se em nossas experiências futuras a realidade simulada tiver um impacto causal maior sobre nossa experiência vivida e comportamento real do que a realidade não simulada, então, num sentido pragmático, ela será mais real" (WEBERMAN, 2003, p. 258). Na verdade, entendo que já começamos a passar por esse impacto e, nesse sentido, precisamos estudar esse fenômeno.

Com isso, faz-se necessária a investigação sobre as possibilidades educacionais que possam emergir no decorrer da formação com professores de matemática e com Tecnologias Digitais, de forma a entender a relação do "ser" com a tecnologia. Fundamentalmente, investigar a inserção dessas tecnologias na Educação Matemática, uma vez que essa proposta poderá evidenciar de que forma a produção do conhecimento

\footnotetext{
7 "We enjoy the movement familiar world, the feeling of alertness that comes from being in this new place, and the delight that comes from learning to move within it. Immersion can entail a mere flooding of the mind with sensation, the overflow of sensory stimulation experienced in the televisor parlor in Bradbury's Fahrenheit 451. Many people listen to music in this way, as a pleasurable drowning of the verbal parts of the brain. But in participatory medium, immersion implies learning [...] to do the things that the new environment makes possible".
} 
matemático pertencente hiperrealisticamente à Realidade Virtual conectada à Realidade Mundana, por meio da Realidade Aumentada, pode vir à tona.

\section{Metodologia subversiva}

A Pesquisa Qualitativa por si só, nesse caso, concede suporte efetivo à relação entre visão de mundo, visão conhecimento e procedimentos metodológicos de investigação defendidos nesse estudo. Essa escolha se deu, porque é imprescindível a percepção de um amplo espectro de indícios que possam responder a pergunta referente ao processo, ou seja, buscarei indícios referentes a um meio e não a um fim. Esses indícios ligam-se diretamente às escolhas que estou fazendo no decorrer de todo o processo. Entretanto, não são escolhas simples, não são quaisquer escolhas, mas àquelas que dependem das vivências, crenças e conhecimentos dos sujeitos envolvidos (ROSA, 2008). Essas escolhas, então, devem manter em consonância a visão de mundo, de conhecimento e procedimentos metodológicos a serem adotados, de forma a desvelar as percepções, concepções e conceitos provenientes dos dados da pesquisa (ARAÚJO; BORBA, 2004).

Assim, busco evidenciar "De que modo" as experiências estéticas possíveis de serem promovidas com o uso de Tecnologias Digitais de Realidade Aumentada, em práticas educativas matemáticas, podem transformar/potencializar a formação do professor de matemática. Com isso, encontro-me no momento de realizar a análise dos dados produzidos no Brasil com professores de matemática que participaram do curso de extensão de 40h intitulado "Cyberformação com professores de matemática: o uso de Tecnologias de Realidade Aumentada". Esse curso teve encontros presenciais nos quais houve introdução à Realidade Aumentada, ao Software Blender ${ }^{8}$ e ao App Andar ${ }^{9}$; planejamento e construção de atividades matemáticas com Realidade Aumentada utilizando o Blender e o Andar; e apresentação e discussão teórica sobre as atividadesmatemáticas-com-Realidade-Aumentada desenvolvidas. A partir disso, se faz profícua a análise do processo de desenvolvimento de atividades-matemáticas-com-RA, uma vez que se torna importante investigar o design de atividades sob uma abordagem construcionista, com matemática dinâmica, em termos de cognição corporificada e em micromundos correlacionados à formação de professores com Tecnologias Digitais (aspectos que envolvem esse projeto de pesquisa).

A análise perpetuará o design iterativo com o objetivo de mediar o conhecimento pessoal dos alunos (HEALY, 2002), com Construcionismo, micromundos e com abordagens e artefatos situados e corpóreos cujo uso atravessa fronteiras entre diferentes práticas (HEALY; KYNIGOS, 2010) e com exemplos de matemática dinâmica, o que

\footnotetext{
8 "Blender é um programa de computador que permite, por exemplo, a modelagem de objetos virtuais 3-D, a edição de suas superfícies, a iluminação do ambiente no qual o objeto está inserido, a animação articulada do objeto, a programação de scripts para, inclusive, a montagem de um filme ou um desenho" (BULLA, 2016, p. 14, nota de rodapé 4).

9 "AndAR é um aplicativo para dispositivos como smartphones ou tablets, capaz de reproduzir objetos virtuais 3-D (criados, por exemplo, no programa Blender) em um ambiente real, ou seja, no ambiente capturado pela própria câmera do smartphone ou tablet. A imagem do objeto virtual 3-D é vista na tela do smartphone ou tablet conforme sua localização no ambiente real, capturada pelas câmeras dos aparelhos mencionados" (BULLA, 2016, p. 14, nota de rodapé 5).
} 
Synclair e Healy (2009) chamam de "dynagraphs" (gráficos dinâmicos). No caso dessa pesquisa, denominamos de holográficos ${ }^{10}$ pois tomam características similares, mas, adentram a Realidade Aumentada e extrapolam a questão dinâmica e corpórea ao se usar o smartphone como lente de aumento.

Além disso, um possível caminho, entre outros a serem vislumbrados, para analisar os dados será utilizar a estrutura teórica proveniente das concepções de intencionalidade (BICUDO; ROSA, 2010, HEIDDEGER, 1988), contempla-ação (BAKHTIN, 2011), construção de conceitos (DELEUZE, GUATTARI, 2005) e outras possibilidades que venham a se constituir teoricamente. Acreditamos que será possível vislumbrar relações entre 0 que defende a Cyberformação e as atividades-com-TD de RA produzidas e vivenciadas em virtude da construção do conceito matemático (NUNES, 2011), pois, a Experiência Estética liga-se a esse movimento de se estar-com a tecnologia e todo o contexto que essa gera, de forma a plugar o "ser" e possivelmente transformar o seu ato de conhecer. Entendo esse aspecto como um princípio Heiddegeriano estabelecido no ser-aíno-mundo (HEIDDEGER, 1988).

Com isso, algumas possibilidades de análise de dados já são vislumbradas, por exemplo, a que apresentamos nesse artigo. Ou seja, perceber (SEIDEL; ROSA, 2013) de que modo experiências estéticas possíveis de serem promovidas com o uso de Tecnologias Digitais de Realidade Aumentada em práticas educativas matemáticas que foram vivenciadas no curso de extensão ofertado pela Universidade Federal do Rio Grande do Sul no ano de 2017, podem transformar/potencializar a Cyberformação com professores de matemática. Farei isso sob uma análise teórica que ressalte essa questão. No entanto, entendo que a finalização da pesquisa abrirá outros caminhos de produção de atividades, de material e de interação que poderão gerar diferentes possibilidades educacionais.

No momento, a pesquisa encontra-se na fase de transcrição, identificação, seleção e análise dos dados produzidos no decorrer do curso de extensão "Cyberformação com professores de matemática: o uso de Tecnologias de Realidade Aumentada". Após transcrição das filmagens gravadas no decorrer da produção de dados, identificarei a partir de uma leitura atenta das transcrições, aqueles momentos que favoreçam responder a pergunta diretriz. Selecionaremos os dados a serem apresentados e os agruparemos por meio de uma categorização, de forma a analisá-los frente ao referencial teórico que sustentar as respostas ao interrogado. Após essas fases de pesquisa, realizaremos a redação dos resultados.

\section{Articulando as considerações finais}

Por esse artigo ser resultado de uma proposta de pesquisa apresentada no I ICOCIME - International Conference on Creative Insubordination in Mathematics Education, ainda não traz os resultados da pesquisa apresentada, uma vez que essa se

\footnotetext{
${ }^{10}$ O vocábulo "holográficos" é constituído a partir da ideia gráficos com aspectos de hologramas. No entanto, mesmo não sendo hologramas propriamente ditos, conforme Ciência Viva (2017), o vocábulo traduz particularidades dos gráficos que são visualizados a partir de recursos de Realidade Aumentada (em 3D), como diferencial de gráficos gerados em softwares. Ou seja, assume características particulares desse tipo de gráfico.
} 
encontra em andamento. No entanto, mesmo que a análise dos dados ainda não tenha sido efetuada, há expressões empíricas evidenciadas em uma leitura prévia dos dados possíveis de serem articuladas. Essas já podem indicar alguns possíveis resultados a serem produzidos em artigos futuros.

Essa pesquisa objetiva investigar as experiências estéticas promovidas com Tecnologias Digitais (TD) de Realidade Aumentada (RA), enquanto transformadoras/potencializadoras da Cyberformação com professores de matemática. Nesse sentido, como Turkle $(1989,1997)$, a qual considera o computador como objeto evocativo, ou seja, aquele que instiga o pensamento; estendo essa ideia às tecnologias de Realidade Aumentada (RA) analisando as experiências estéticas produzidas no decorrer da produção de dados dessa pesquisa. De antemão, já afirmo que as TD de RA são objetos evocativos, pois, vejo-as a uma "[...] luz diferente, não em termos da sua natureza como 'engenho analítico', mas em termos de sua 'segunda natureza' como objecto evocativo, um objecto que fascina, perturba a tranqüilidade e estimula o pensamento" (TURKLE, 1989, p.15, grifo nosso). Também, afirmo que as TD de RA, frente às várias pesquisas já desenvolvidas e em desenvolvimento, também sob o viés da Cyberformação com professores de matemática, geram experiências estéticas proeminentes quando se desenvolve atividades-matemáticas-com-TD de RA. Devido a isso, entendo que tanto a Cyberformação com professores, quanto os processos de ensino e de aprendizagem de matemática, vivenciados pelos docentes (participantes da produção de dados realizada em 2017) e por seus alunos sofrem transformações a partir de ações como ser-com, pensarcom e saber-fazer-com-TD de RA (BULLA; ROSA, 2017). Assim, a construção de conceitos matemáticos com a Realidade Virtual (BICUDO; ROSA, 2010) e, consequentemente nesse caso, com a Realidade Aumentada, pode abrir e ampliar possibilidades de conjecturas e de formação de profissionais que vivenciem esses conceitos a partir da antecipação de sua prática com o meio virtual/mundano.

Com isso, é possível a compreensão das possibilidades educacionais que podem emergir no decorrer da Cyberformação com professores de matemática em um curso de extensão que trabalhou com a elaboração dessas atividades e previu o seu uso em sala de aula. Não obstante, essas possibilidades educacionais se mostram de modo a se identificar as possíveis transformações que o uso dessas tecnologias pode trazer à Educação Matemática como um todo, contribuindo para esse campo de pesquisa. Principalmente, tratando-se de inserções características da Insubordinação Criativa.

\section{Referências}

ABBAGNANO, N. Dicionário de Filosofia. São Paulo: Martins Fontes, 2003.

ALVES, L. Ensino Online: trilhando novas possibilidades pedagógicas mediadas pelos jogos eletrônicos. Universidade do Estado da Bahia.

<http://www.comunidadesvirtuais.pro.br/ead/artigo.pdf\#search=\%22RPG\%20multiplayer\% 20PUC\%22>. Acesso em: 20 ago. 2006.

ARAÚJO, J. L.; BORBA, M. C. Construindo Pesquisas Coletivamente em Educação Matemática. In: BORBA, M. C.; ARAÚJO, J. L. (Org.). Pesquisa Qualitativa em

Educação Matemática. Belo Horizonte: Autêntica, 2004. p. 25-45. 
BAIRRAL, M. A. Compartilhando e Construindo Conhecimento Matemático: análise do discurso nos chats. Bolema - Boletim de Educação Matemática. Rio Claro, Ano 17. n. 22, p. 37-61, 2004.

BAKHTIN, M. M. Estética da criação verbal. 6. ed. São Paulo: Martins Fontes, 2011.

BICUDO, M. A. V. Experiência e experiência vivida In: TOURINHO, C.; BICUDO, M. A. V. (Org.). A Fenomenologia e seus influxos. Rio de Janeiro: Booklink, 2010.

BICUDO, M. A. V.; ROSA, M. Realidade e cibermundo: horizontes filosóficos e educacionais antevistos. Canoas: ULBRA, 2010.

BULLA, F. D. Modelagem Matemática na perspectiva da Realidade Aumentada: possibilidades à formação de professores. 2016. Trabalho de Conclusão de Curso (Licenciatura em Matemática). Departamento de Matemática Pura e Aplicada.

Universidade Federal do Rio Grande do Sul. Porto Alegre. 2016.

BULLA, F. D.; ROSA, M. O Design de Tarefas-Matemáticas-com-Realidade-Aumentada: uma autorreflexão sobre o processo. Acta Scientiae. Canoas (RS), v.19, n.2, p.296-319, 217. Disponível em: < http://www.periodicos.ulbra.br/index.php/acta/article/view/ 3036/2304>. Acesso em: 13 jun. 2017.

CALDEIRA, J. P. S. Cyberformação Mobile de Professores de Matemática. 2013. Projeto de Pesquisa (Mestrado em Ensino de Ciências e Matemática), Universidade Luterana do Brasil, Canoas, 2013.

CIÊNCIA VIVA. Hologramas. Disponível em: <http://www.cienciaviva.pt/projectos /pulsar/hologramas.asp>. Acesso em: 16 jun. 2017.

D'AMBRosiO, U. A Educação Matemática e o Estado do Mundo: desafios. Em Aberto, Brasília, v.27, n.91, p.157-169, 2014. Disponível em: < http://emaberto.inep.gov.br/ index.php/emaberto/article/view/2402/2362>. Acesso em: 30 ago.2017.

D'AMBROSIO, B. S.; LOPES, C. E. Insubordinação Criativa: um convite à reinvenção do educador matemático. Bolema, Rio Claro, v. 29, n. 51, p. 1-17, 2015 . Disponível em: <http://www.scielo.br/scielo.php?script=sci_arttext\&pid=S0103-636X2015000100002 \&lng=en\&nrm=iso>. Acesso em: 30 ago. 2017.

DELEUZE, G.; GUATTARI, F. O que é filosofia? 2. ed. Tradução: Bento Prado Jr. E Alberto Alonso Muñoz, 2005.

DUNHAM, P. H.; DICK, T. P. Research on Graphing Calculators. Mathematics Teacher, vol. 87, p. 440-445, 1994

JAHN, A. P. New tools, new attitudes to knowledge: the case of geometric loci and transformations in Dynamic Geometry Environment. In: PME24 - 24th Conference of the International Group the Psychology of Mathematics Education, 2000, Hiroshima.

Proceedings..., Japan : Hiroshima University (Nishiki Print Co., Ltd.), 2000. v. 1. p. 91103.

HEALY, S. V. Iterative Design and Comparison of Learning Systems for Reflection in Two Dimensions. 2002. Dissertation (Doctorate in Mathematics Education) - Institute of Education, University of London, London, 2002.

HEALY, S. V. ; KYNIGOS, C. Charting the microworld territory over time: design and construction in mathematics education. ZDM Mathematics Education. Hamburg, Germany , v 42, p. 63-76, 2010.

HEIDEGGER, M. Ser e Tempo. Petrópolis: Vozes, 1988. 
KENSKI, V. M. Tecnologias e ensino presencial e a distância. Campinas: Papirus, 2003.

KIRNER, C.; SISCOUTTO, R. Realidade Virtual e Aumentada: Conceitos, Projetos e Aplicações. Livro do Pré-Simpósio; IX Symposium on Virtual and Augmented Reality, Petrópolis - RJ, 2007.

LÉVY, P. A Inteligência Coletiva: por uma antropologia do ciberespaço. Tradução Luiz Paulo Rouanet. 3. ed. São Paulo: Edições Loyola, 2000a.

Cibercultura. Tradução: Carlos Irineu da Costa. 2. ed. São Paulo: Editora 34,

$2000 b$.

\section{MACHADO, E. L. F. A Experiência Estética da Matemática com a Realidade}

Aumentada: contribuições para a formação de professores. 2016. Trabalho de Conclusão de Curso (Licenciatura em Matemática). Departamento de Matemática Pura e Aplicada. Universidade Federal do Rio Grande do Sul. Porto Alegre. 2016.

MARTINS, M. C. Criança e mídia: "Diversa-mente" em ação em contextos educacionais. Tese (Doutorado em Multimeios) - UNICAMP, Campinas, 2003.

MERLEAU-PONTY, M. Fenomenologia da Percepção. Tradução: Carlos Alberto Ribeiro de Moura. 3. ed. São Paulo: Martins Fontes, 2006. 662 p.

MUSSATO, S.; ROSA, M. Cyberformação: uma proposta em consonância com a mlearning. In: XVI ENCONTRO BRASILEIRO DE ESTUDANTES DE PÓS-GRADUAÇÃO EM EDUCAÇÃO MATEMÁTICA, 16., 2012, Canoas. Anais... Canoas: SBEM, 2012.

MURRAY, J. H. Hamlet on the Holodeck: the future of narrative in cyberspace. New York: Free Press, 1997.

NOSS, R.; HOYLES, C. Constructionism and Microwords. In.: DUVAL, E.; SUTHERLAND, R.; SHARPLES, M. (Ed.), The Technology Enhanced Learning: Research Themes. Springer, 2015.

NUNES, J. A. Design Instrucional de Atividades sobre Funções Trigonométricas com Calculadoras Gráficas. Dissertação (Mestrado em Ensino de Ciências e Matemática) Universidade Luterana do Brasil, 2011.

PENTEADO, M. G. Computer-based learning environments: risks and uncertainties for teachers. Ways of Knowing, Inglaterra, v. 1, n. 2, p. 23-35, 2001.

PEI-LUEN P. R.; QIN G.; LI-MEI W., Using mobile communication technology in high school education: Motivation, pressure, and learning performance. Computers \& Education, Elsevier B.V., v. 50, n. 1, 2008, p.1-22. Disponível em:

<http://dx.doi.org/10.1016/j.compedu. 2006.03.008>. Acesso em: 30 ago. 2017.

RESENDE, B. Realidade Aumentada e Interfaces Naturais na Formação do Professor de Matemática. 2016. Trabalho de Conclusão de Curso (Licenciatura em Matemática). Departamento de Matemática Pura e Aplicada. Universidade Federal do Rio Grande do Sul. Porto Alegre. 2016.

ROSA, M. Role Playing Game Eletrônico: uma tecnologia lúdica para aprender e ensinar matemática. 2004. Dissertação (Mestrado em Educação Matemática) - Instituto de Geociências e Ciências Exatas, Universidade Estadual Paulista, Rio Claro, 2004.

A Construção de Identidades Online por meio do Role Playing Game:

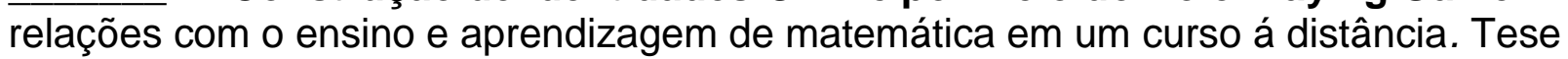
(Doutorado em Educação Matemática) - UNESP, Rio Claro, 2008. 
Cultura Digital, Práticas Educativas e Experiências Estéticas: interconexões com a Cyberformação de Professores de Matemática. In: REUNIÃO ANUAL DA ANPED, 34., 2011, Natal, RN. Anais... Natal, RN: ANPED, 2011.

Cyberformação com Professores de Matemática: interconexões com

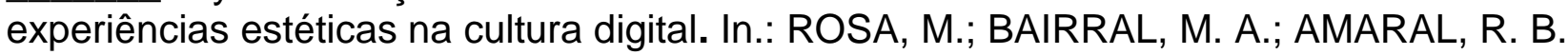

Educação Matemática, Tecnologias Digitais e Educação a Distância: pesquisas contemporâneas. São Paulo: Editora Livraria da Física, 2015, p.57-93.

ROSA, M. BAIRRAL, M. A. Curriculum for Prospective Mathematics Teachers Using Digital Technologies: a proposal enhanced by Creative Insubordination. In.: D'AMBROSIO, B. S.; LOPES, C. E. (Ed.) Creative Insubordination in Brazilian Mathematics Education Research. Raleigh: Lulu Press, 2015, p. 171-185.

ROSA, M. BICUDO, M. A.V. Focando a Constituição do Conhecimento Matemático que se Dá no Trabalho Pedagógico que Desenvolve Atividades com Tecnologias Digitais. In.: PAULO, R. M.; FIRME, I. C.; BATISTA, C. C. Ser professor com tecnologias: sentidos e significados. São Paulo, Editora da UNESP, 2018. (no prelo)

SEIDEL, D. J.; ROSA, M. Possibilidades da percepção fenomenológica nos procedimentos investigativos da pesquisa qualitativa em Educação Matemática. Educação Matemática

Pesquisa. São Paulo, v. 16, n. 2, 2014.

SCUCUGLIA, R. A investigação do teorema fundamental do cálculo com calculadoras gráficas. 2006. Dissertação (Mestrado em Educação Matemática) - Instituto de Geociências e Ciências Exatas, Universidade Estadual Paulista, Rio Claro, 2006.

SOUZA, R.; MOREIRA, H. D. F.; KIRNER, C. FLARAS 1.0 - Flash Augmented Reality Authoring System, e-book, 2012. Disponível em: <http://ckirner.com/flaras2 /wpcontent/uploads/2012/09/ivro-flaras.pdf>. Acesso em: 03 mai. 2013

TURKLE, S. O Segundo Eu: os computadores e o espírito humano. Tradução: Manuela Madureira. Lisboa: Editorial Presença, 1989.

TURKLE, S. A Vida no Ecrã: a Identidade na Era da Internet. Tradução: Paulo Faria. Lisboa: Relógio D’Água Editores, 1997. Tradução de: Life on the Screen: identity in the age of the Internet. New York: Touchstone Edition, 1995.

VANINI, L.; ROSA, M.; JUSTO, J. C. R.; PAZUCH, V. Cyberformação de Professores de Matemática: olhares para a dimensão tecnológica. Acta Scientiae. Canoas, v. 15, p. 153171, 2013.

WEBERMAN, D. A Simulação de Matrix e a Era Pós-Moderna. In: IRWIN, W. Matrix: bemvindo ao deserto do real. Tradução Marcos Malvezzi Leal. São Paulo: Masdras, 2003. p. 247-258. Título Original: The Matrix and Plilosophy: Welcome to the Desert of the Real.

Submissão: 25/07/2017

Aceite: 16/11/2017 